\title{
Evidence for intragenic recombination within a novel genetic marker that distinguishes mussels in the Mytilus edulis species complex
}

\author{
PAUL D. RAWSON, KAREN L. JOYNER, KEITH MEETZE \& THOMAS J. HILBISH* \\ Department of Biological Sciences, University of South Carolina, Columbia, SC 29201, U.S.A.
}

\begin{abstract}
We have used the polymerase chain reaction (PCR) and restriction fragment length polymorphism (RFLP) techniques to design two genetic markers for blue mussels in the Mytilus edulis species complex. Both of these markers target the gene encoding the mussel polyphenolic adhesive protein. The first marker, Glu-5', is highly differentiated among and can be used to identify the three blue mussel species, $M$. edulis, $M$. galloprovincialis and $M$. trossulus. The second marker, Glu-3', can identify $M$. edulis and $M$. galloprovincialis. Using these markers we have demonstrated that hybrid mussels from Whitsand Bay, UK carry alleles for this gene that are the products of intragenic recombination. The high frequency (10 per cent) of these recombinant alleles within the hybrid population suggests that recombination is fairly frequent within this gene or that hybridization between $M$. edulis and $M$. galloprovincialis is substantial and has been occurring over considerable evolutionary time. The two novel genetic markers, $G l u-5^{\prime}$ and $G l u-3^{\prime}$ will be invaluable in additional studies regarding the importance of hybrization among blue mussels.
\end{abstract}

Keywords: intragenic recombination, Mytilus, population genetics, polyphenolic adhesive protein.

\section{Introduction}

Studies of natural hybridization can reveal patterns of linkage disequilibrium, selection, recombination and introgression between populations which are genetically differentiated, providing valuable insight into the genetic basis of adaptive evolution and speciation (Barton \& Hewitt, 1985; Harrison \& Rand, 1989). Although hybrid zones appear to be a common phenomenon, the vast majority of welldocumented occurrences of natural hybridization are for terrestrial taxa (see Barton \& Hewitt, 1985; Hewitt, 1990). However, natural hybridization may also figure prominently in the biology and evolution of many marine taxa, including blue mussels in the Mytilus edulis species complex. This complex is composed of three morphologically similar species or subspecies in the Northern Hemisphere, $M$. edulis, $M$. galloprovincialis, and $M$. trossulus, (McDonald et al., 1991). The status of these taxa is actively debated (Koehn, 1991; Gosling, 1992a);

*Correspondence.

(C) 1996 The Genetical Society of Great Britain. however, allopatric populations of these taxa are genetically distinct despite natural hybridization that occurs wherever any two of the taxa are sympatric (Gosling, 1992b).

Case studies of natural hybridization rely on an extensive suite of well-differentiated molecular and morphological genetic markers for determining the genotypic class to which an individual belongs (Avise, 1994). For Mytilus spp., detailed hybrid zone analysis has been complicated by an insufficient number of genetic markers. Allozymes have been used extensively for taxonomic characterization and assessment of selection in natural populations of Mytilus spp. (reviewed by Gosling, 1992b). Of the allozymes employed to date, four are well differentiated but not diagnostic between any pair of blue mussel species. Morphological characters can occasionally be used to identify mussel species on a local basis (Freeman et al., 1994) but are less reliable over larger spatial scales (Gosling, 1992b). Thus, to study the importance of hybridization to the evolution of blue mussels it is necessary to develop additional genetic markers that diagnostically identify the three 
species within the $M$. edulis species complex and allow accurate estimation of the frequency of various genotypic classes within mussel hybrid zones.

The advent of modern molecular biological techniques, including the polymerase chain reaction (PCR), provides the opportunity to develop these new genetic markers and to apply these techniques to life stages of mussels that cannot be routinely analysed using allozymes. For example, Corte-Real et al. (1994a,b) report the development of a $M$. edulis CaM-1 intron 3 marker using intron-targeted PCR. They further show that this marker is polymorphic within hybrid mussel populations in western Europe, has relatively low levels of local differentiation and is likely to be neutral. However, Corte-Real et al. (1994a,b) present no information on whether the CaM-1 marker is differentiated among allopatric populations of the three taxa in the $M$. edulis species complex.

We have used PCR to detect polymorphism at the nuclear locus encoding the mussel polyphenolic adhesive protein. This protein is produced by the endocrine gland in the foot of a mussel and is a key component in the attachment of mussels to the substratum (Waite, 1992). The primary sequence of this protein is highly differentiated between $M$. edulis and M. galloprovincialis (Filpula et al., 1990; Inoue \& Odo, 1994). We have designed two separate sets of oligonucleotide primers for specific regions in the $5^{\prime}$ and $3^{\prime}$ ends of the approximately 2.5 kilobase 'giant exon' of this gene. Using these primer sets and PCR, we have designed one assay which identifies all three species within the $M$. edulis complex and a second assay which identifies $M$. edulis and $M$. galloprovincialis. Herein, we report the development of these assays, their application to the study of hybridization in Mytilus spp. from southwestern England and the identification of individual mussels carrying recombinant genotypes at the polyphenolic adhesive protein locus.

\section{Materials and methods}

We constructed genetic markers for the $5^{\prime}$ and $3^{\prime}$ ends of a gene that encodes a polyphenolic adhesive protein used by mussels to attach byssal threads to substrate (Waite, 1992). For brevity we have named this the Glu locus. The Glu gene has been cloned and sequenced for both $M$. edulis (Filpula et al., 1990) and M. galloprovincialis (Inoue \& Odo, 1994); the last approximately 875 amino acid residues of the protein are encoded by a single large exon (approximately $2.5 \mathrm{~kb}$ ) and are mainly arranged in tandem decapeptide repeats (Filpula et al., 1990).

\section{Glu-5' marker}

Oligonucleotide primers were designed from the DNA sequences reported by Filpula et al. (1990) for M. edulis. The first primer (JH-5; GTAGGAACAAAGCATGAACCA) corresponds to the extreme $5^{\prime}$ end of the $2.5 \mathrm{~kb}$ giant exon. For the reverse primer (JH-54; GGGGGGATAAGTTTTCTTAGG) we aligned the primary sequences for the decapeptide repeats within the giant exon. This primer was designed to anneal to only a subset of these repeats by anchoring most of the primer in the repeat but with the $3^{\prime}$ end of the primer annealing to the more variable regions upstream of the repeats. Amplifications were performed by the polymerase chain reaction using $50 \mathrm{ng}$ of total DNA, $2.5 \mathrm{nmol}$ of dNTPs, $50 \mathrm{pmol}$ of each primer and $0.5 \mathrm{U}$ Taq polymerase. Each reaction was conducted in a total volume of $12.5 \mu \mathrm{L}$ using an amplification buffer supplied by the manufacturer (US Biochemical) and $1.5 \mathrm{~mm}$ of $\mathrm{MgCl}_{2}$. The samples were denatured initially for $3 \mathrm{~min}$ at $94^{\circ} \mathrm{C}$ and then incubated for 30 cycles of $94^{\circ} \mathrm{C}$ for 20 $\mathrm{s}, 53^{\circ} \mathrm{C}$ for $20 \mathrm{~s}$, and $72^{\circ} \mathrm{C}$ for $45 \mathrm{~s}$. PCR products were then resolved on 2.5 per cent agarose gels.

\section{Glu-3' marker}

A second set of primers was designed to amplify the extreme $3^{\prime}$ end of the giant exon. Primer JH-4 (CTTTCAAATGTTCATCTGTTCCTC) anneals to a site in the $3^{\prime}$ untranslated region (UTR) that Filpula et al. (1990), Inoue \& Odo (1994) and our own sequence information (data not shown) have indicated is conserved between $M$. galloprovincialis and $M$. edulis. Primer PR-8 (AAGCCAAGTTATCCTCCAAC) anneals to the region designated as repeat 77 in the $M$. edulis sequence of Filpula $e t$ al. (1990) and the corresponding repeat in M. galloprovincialis. PCR was performed with these primers as described above except that the annealing temperature was lowered to $45^{\circ} \mathrm{C}$ for 30 cycles.

This assay produced an approximately 220 base pair product in both $M$. edulis and $M$. galloprovincialis but did not amplify any product from $M$. trossulus. Following amplification, $6 \mu \mathrm{L}$ of PCR product was digested with $5 \mathrm{U}$ of the restriction enzyme $D d e \mathrm{I}$ in $18 \mu \mathrm{L}$ of buffer supplied by the manufacturer (New England Biolabs). Restriction fragments were subsequently resolved on 2.5 per cent agarose gels.

\section{Reference populations}

Adult blue mussels were collected from six intertidal 
sites containing allopatric populations of $M$. edulis (Lewes, DE and Cape Anne, MA, USA), M. galloprovincialis (San Diego, CA, USA, and Sete, France) and $M$. trossulus (Newport and Port Orford, OR, USA). Total cellular DNA was extracted from individual mussels from each site by digesting a $50 \mathrm{mg}$ subsample of tissue for $3 \mathrm{~h}$ at $55^{\circ} \mathrm{C}$ in $300 \mu \mathrm{L}$ lysis buffer (50 mM Tris- $\mathrm{HCl}, \mathrm{pH}$ 8.0; 1 per cent SDS; 25 mM EDTA) with $100 \mu \mathrm{g}$ of proteinase $\mathrm{K}$. The nucleic acids were isolated by extracting the completely digested tissue once with phenol/chloroform $(1: 1)$ followed by precipitation of the DNA with 95 per cent ethanol. The precipitate was washed in 70 per cent ethanol, air-dried and resuspended in $100 \mu \mathrm{L}$ of TE $(10 \mathrm{~mm}$ Tris- $\mathrm{HCl}, 1 \mathrm{~mm}$ EDTA). These DNA extracts were then analysed

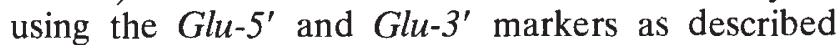
above.

\section{Comparisons with allozyme data}

It is well documented that allozyme alleles characteristic of $M$. edulis exhibit a significant decline in frequency with increasing size or age in hybrid mussel populations in south-west England (Skibinski, 1983; Gardner \& Skibinski, 1988; Wilhelm, 1993). To determine whether the Glu-5' and Glu-3' behave in a similar manner, we collected mussels from Whitsand Bay in south-west England where these patterns have been particularly well established. Mussels were sorted into $5 \mathrm{~mm}$ shell length size classes and 20 individuals were selected from each size class for genetic analysis. Each mussel was dissected, tissue samples taken from the gill, mantle and digestive gland and frozen at $-80^{\circ} \mathrm{C}$. Frozen tissue samples were electrophoresed and stained according to the procedures of Skibinski et al. (1980) for Esterase-D (Est, EC 3.1.1.1) and Leucine aminopeptidase (Lap, EC 3.4.11) and McDonald et al. (1991) for Mannose-6-phosphate isomerase (Mpi, EC 5.3.1.8). Because each of these loci is multi-allelic, we combined alleles to create compound alleles characteristic of $M$. edulis and $M$. galloprovincialis as described Skibinski et al. (1980). Total nucleic acids were extracted from the remaining tissue and

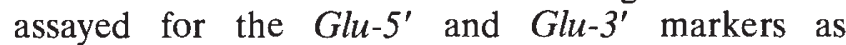
described above.

\section{Results}

\section{Glu-5' marker}

The Glu-5' PCR assay produced species-specific banding patterns as shown in Fig. 1a. In $M$. edulis, this assay produced three different banding patterns; approximately 85 per cent of $M$. edulis mussels produced a single $350 \mathrm{bp}$ band, 3 per cent produced a $380 \mathrm{bp}$ band and 12 per cent produced both bands (Table 1). When this assay was applied to $M$. galloprovincialis mussels, two primary bands of 300 and 500 bp were produced. Occasionally Glu-5' PCR with some $M$. galloprovincialis individuals produced only the $300 \mathrm{bp}$ band. In contrast, Glu-5' PCR with $M$. trossulus consistently produced a single primary band of $240 \mathrm{bp}$. In many of the PCR reactions with primers $\mathrm{JH}-5$ and $\mathrm{JH}-54$ other bands, such as the
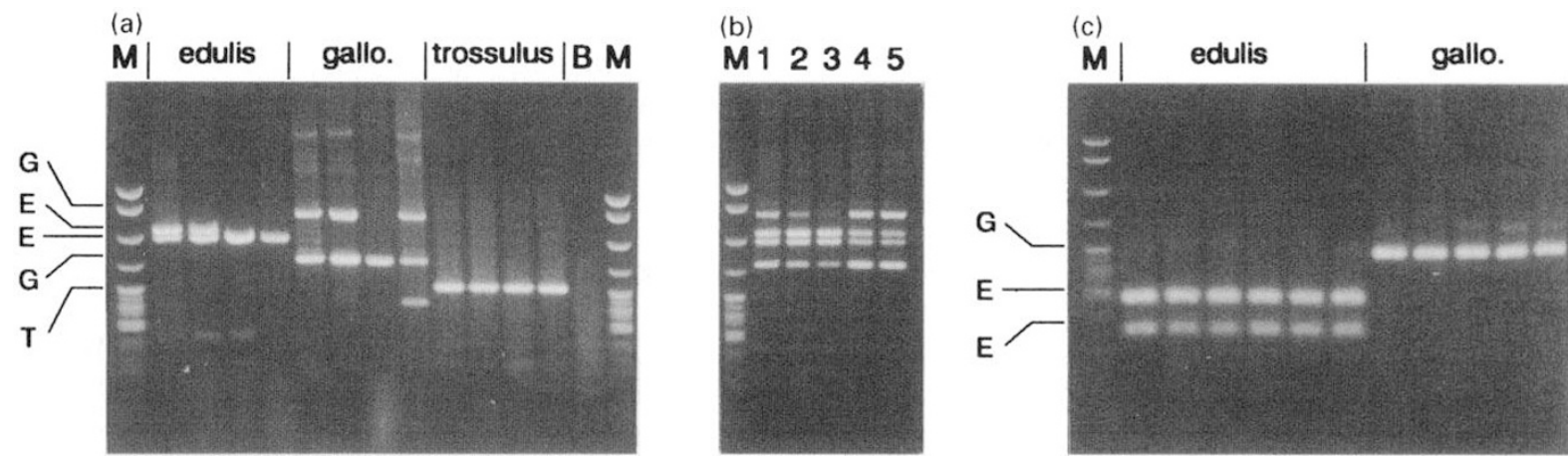

Fig. 1 (a) PCR products generated using the Glu-5' assay for four individuals from Mytilus edulis (edulis), M. galloprovincialis (gallo.) and $M$. trossulus (trossulus). The size marker (lane $\mathrm{M}$ ) is pBR322 digested with MspI and the negative control is in lane B. The species-specific banding patterns are indicated on the left (E, M. edulis bands; G, M. galloprovincialis bands; T, M. trossulus bands). (b) Glu-5' sensitivity analysis. DNA from M. edulis and M. galloprovincialis was mixed at ratios of 1:1, 1:3, 1:5, 3:1 and 5:1 and the Glu-5' PCR results are in lanes 1-5, respectively. (c) Restriction fragment profiles from the Glu-3' assay for six M. edulis and five M. galloprovincialis individuals. Species designations and marker lanes are the same as in Fig. 1a. 
Table 1 Frequency of individuals with $G l u-5^{\prime}$ or $G l u-3^{\prime}$ banding patterns in allopatric populations of Mytilus trossulus (Newport and Pt. Orford), M. edulis (Lewes and Cape Anne) and M. galloprovincialis (San Diego and Sete)

\begin{tabular}{|c|c|c|c|c|c|c|c|c|c|c|c|}
\hline \multirow[b]{2}{*}{ Location } & \multicolumn{8}{|c|}{ Band size: $G l u-5^{\prime}$} & \multicolumn{3}{|c|}{ Band size: $G l u-3^{\prime}$} \\
\hline & $n$ & 240 & 350 & 380 & $350 / 380$ & 300 & 500 & $300 / 500$ & $n$ & 214 & $130 / 90$ \\
\hline Newport, OR & 42 & 100 & 0 & 0 & 0 & 0 & 0 & 0 & - & - & - \\
\hline Pt. Orford, OR & 24 & 100 & 0 & 0 & 0 & 0 & 0 & 0 & - & -- & - \\
\hline Lewes, DE & 25 & 0 & 76 & 8 & 16 & 0 & 0 & 0 & 33 & 0 & 100 \\
\hline Cape Anne, MA & 36 & 0 & 92 & 0 & 8 & 0 & 0 & 0 & 36 & 0 & 100 \\
\hline San Diego, CA & 64 & 0 & 0 & 0 & 0 & 3 & 0 & 97 & 64 & 100 & 0 \\
\hline Sete, France & 17 & 0 & 0 & 0 & 0 & 6 & 0 & 94 & 17 & 100 & 0 \\
\hline
\end{tabular}

For the $G l u-5^{\prime}$ marker, only the primary bands were scored (see text). The dashes under the Glu-3' columns indicate that this marker could not be amplified for $M$. trossulus

200 bp product for the M. galloprovincialis individual shown in Fig. 1, were generated. These were probably produced by the reverse primer $\mathrm{JH}-54$ annealing at other repeat sites within the polyphenolic adhesive gene. However, none of these minor bands was of the same length as the primary bands. Thus, there was some level of band polymorphism within each species but these polymorphisms did not overlap and the primary banding patterns were specific to the allopatric population samples of each species (Table 1).

We have cloned and sequenced the primary Glu-5' products generated for each of the three Mytilus ssp. in this study. The sequences (Fig. 2) show that the different products resulting from PCR with $M$. edulis are more closely related to each other than they are to the two products from $M$. galloprovincialis and vice versa. From these sequences it is also evident that the annealing site for the $M$. edulis $350 \mathrm{bp}$ band has been significantly disrupted in the $380 \mathrm{bp}$ band. If these banding patterns are treated as separate alleles, the $G l u-5^{\prime}$ genotype frequencies within both $M$. edulis reference populations do not deviate from Hardy-Weinberg equilibrium $(G=0.811$; NS). We, therefore, feel that these PCR products are produced by two distinct and well differentiated alleles. In contrast, the $M$. galloprovincialis $500 \mathrm{bp}$ product contains an intact annealing site coincident with the annealing site for the $M$. galloprovincialis $300 \mathrm{bp}$ product. We feel that the observed variation in banding pattern among $M$. galloprovincialis individuals may be produced by small differences in nucleotide sequence at the annealing site for primer JH-54. Alternatively, slight variation in PCR conditions may result in the $300 \mathrm{bp}$ band of $M$. galloprovincialis being preferentially amplified. These two possibilities are not mutually exclusive. We have tested this assay repeatedly on a small set of samples and found that occasionally some individuals produce two primary bands in one reaction and only a single primary band in subsequent reactions and vice versa.

Because of this phenomenon, we used a sensitivity analysis to test whether particular species-specific alleles could out-compete others for priming during PCR with hybrid mussels. We mixed DNA from each of two mussel species at ratios of 1:1, 1:3, 1:5, 3:1 and 5:1 and then conducted the Glu $5^{\prime}$ PCR analysis. When we mixed $M$. edulis and $M$. galloprovincialis DNA in this manner we obtained both species-specific primary bands at all dilutions, as shown in Fig. 1b. Similar results were obtained for mixtures containing $M$. trossulus and $M$. galloprovincialis or M. edulis DNA (data not shown).

\section{Glu-3' marker}

PCR with the $G l u-3^{\prime}$ primers produced a $220 \mathrm{bp}$ product in $M$. edulis and a 214 bp product in $M$. galloprovincialis but failed to amplify any product from $M$. trossulus. These products can be resolved on polyacrylamide gels; however, when the PCR products were digested with the restriction enzyme DdeI species-specific restriction fragment patterns that can be separated on agarose gels were generated (Fig. 1c). These patterns were fixed within allopatric populations of $M$. edulis and M. galloprovincialis (Table 1). The difference in restriction patterns was the result of a single base change that lies within the coding region of Glu for $M$. edulis and within the 3' UTR for M. galloprovincialis (Fig. 3). We also tested two other restriction enzymes (NdeI and $M s e I$ ) for the capacity to digest differentially the Glu-3' PCR product and both produced speciesspecific restriction patterns between $M$. edulis and M. galloprovincialis (data not shown). 
Fig. 2 Alignment of $G l u-5^{\prime}$ sequences. The three Mytilus edulis are designated by the letters M.e. and include the published (pub) genomic sequence from Filpula et al. (1990) and one sequence each for the 380 and $350 \mathrm{bp}$ PCR products. The $M$. galloprovincialis sequences are indicated by the letters M.g. and include the published (pub) cDNA sequence from Inoue \& Odo (1994) and one sequence each for the 500 and 350 bp PCR products. The single $M$. trossulus sequence is designated as M.t. (240). Annealing sites for the primers $\mathrm{JH}-5$ and $\mathrm{JH}-54$ are indicated by arrows. Alignment gaps are indicated by dashes and dots denote sequence similarity.

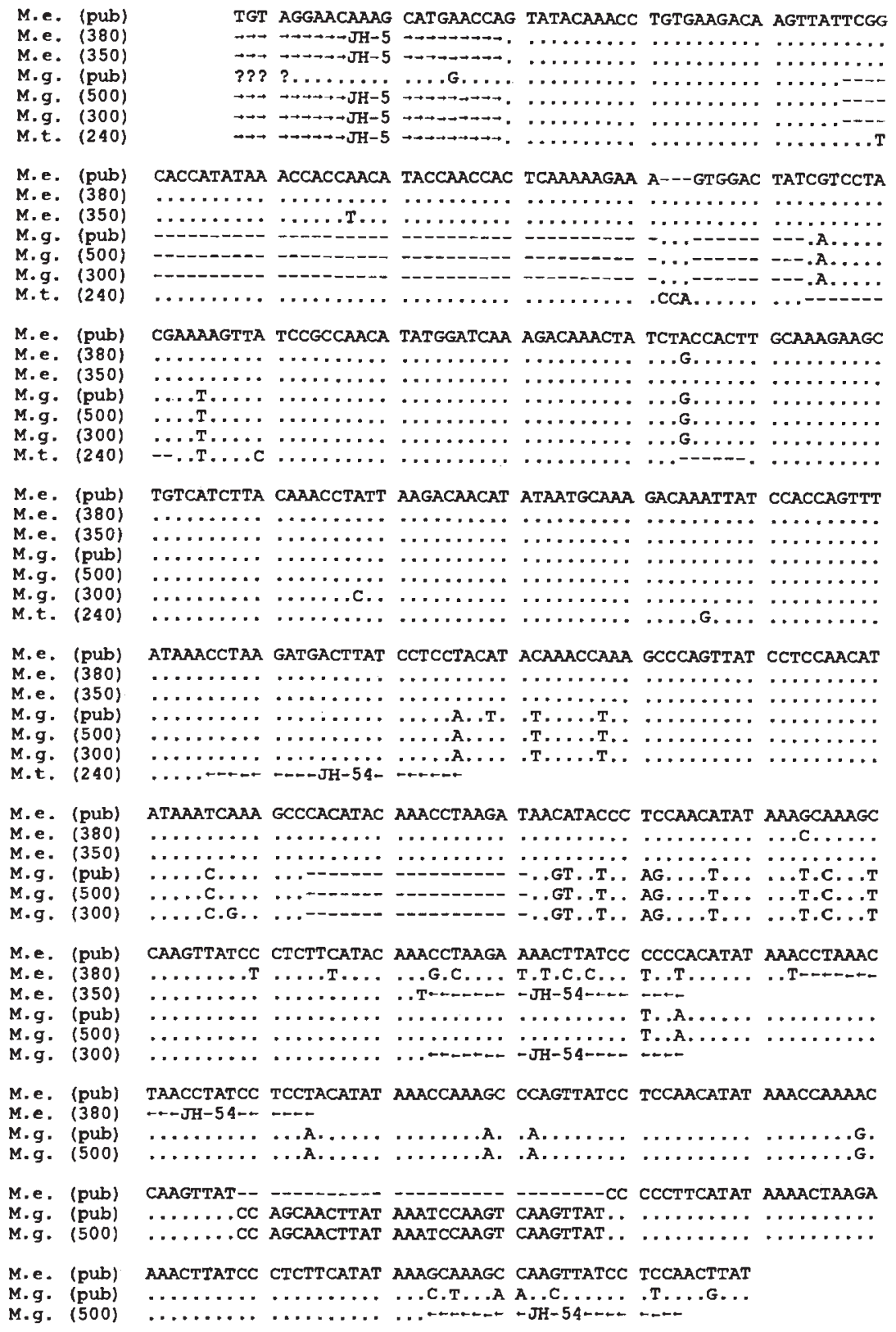

markers and $M p i$ or Lap. This observation was unexpected; because the two Glu markers are physically closely linked we anticipated a perfect correlation between species-specific Glu-5' and Glu-3' allele frequencies across size class. This was not the case as the two markers had unequal allele frequencies and different associations with the allozyme loci. We therefore examined each individual in the sample from Whitsand Bay to determine whether their $G l u-5^{\prime}$ and $G l u-3^{\prime}$ genotypes agreed with one another. Several individuals were detected in which the Glu-5' and Glu-3' genotypes disagreed, indicat- 


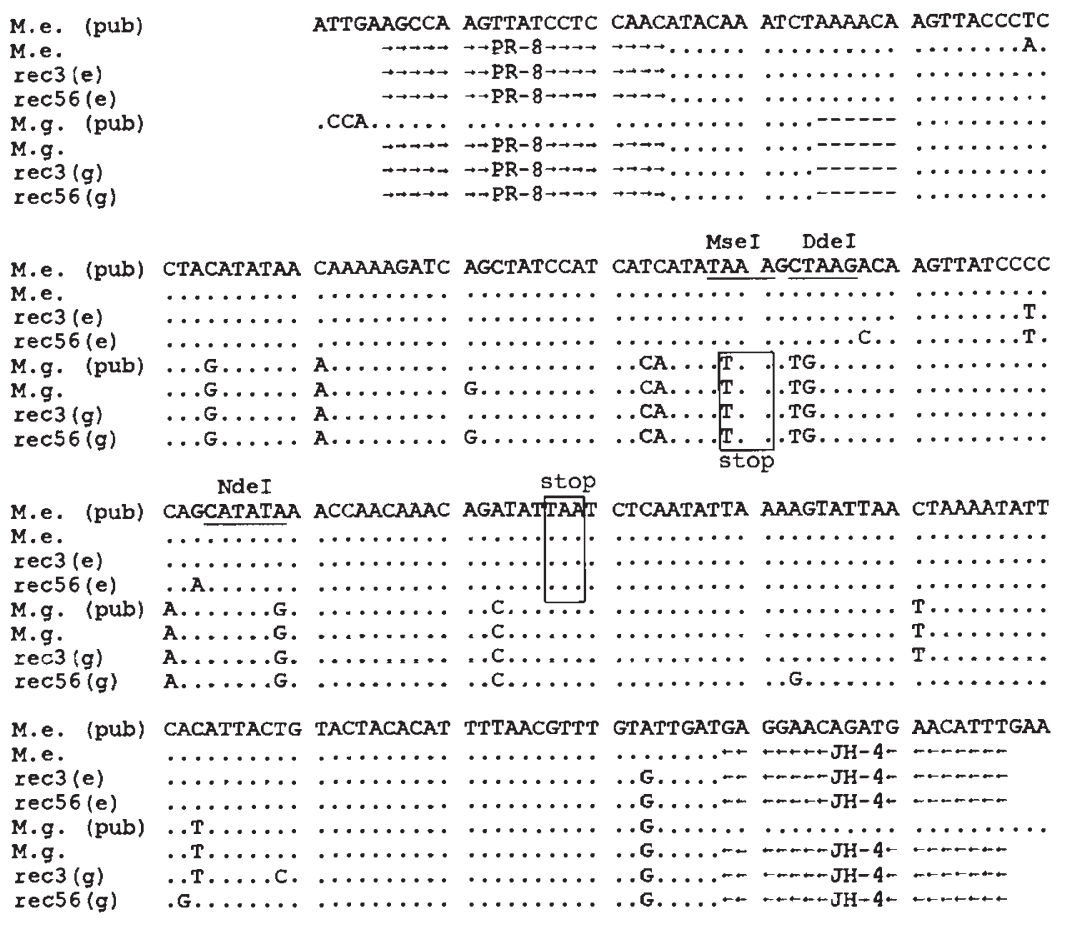

Fig. 3 Alignment of Glu-3'sequences. Mytilus edulis and $M$. galloprovincialis sequences are designated as M.e. and M.g., respectively. Also given are the sequences for edulis (e) and galloprovincialis $(\mathrm{g})$ alleles from two mussels (rec3 and rec56) which carried recombinant genotypes. Annealing sites, for the primers JH-4 and PR-8, alignment gaps and sequence similarity are indicated as in Fig. 2. Restriction sites used in this study are underlined and the stop codon for each taxon is indicated by a box. ing that these mussels carried alleles in which recombination has occurred between the $5^{\prime}$ and $3^{\prime}$ ends of the Glu 'giant' exon. This phenomenon was most pronounced in the $<10 \mathrm{~mm}$ size class (Fig. 5). In cases where the two genotypes disagreed, the majority (57 per cent) were homozygous for an $M$. edulis allele at the Glu-5' marker and were heterozygous at the Glu-3' marker. Of the remainder, 33 per cent were homozygous for the $M$. galloprovincialis allele at the Glu $5^{\prime}$ marker and heterozygous at the Glu 3' marker whereas 10 per cent were heterozygous at the $G l u-5^{\prime}$ marker and homozygous for $M$. edulis or $M$. galloprovincialis alleles at the Glu-3' marker.

\section{Discussion}

We have developed a pair of gene-specific PCR-based genetic markers that reliably identify individual taxa within the $M$. edulis species complex. Both of these markers target the 'giant exon' of the gene encoding the mussel polyphenolic adhesive protein described previously for $M$. edulis (Filpula et al., 1990) and M. galloprovincialis (Inoue \& Odo, 1994); we have designated this the Glu locus. The Glu gene has been characterized as a single locus by Filpula et al. (1990). The first marker, Glu-5', lies at the $5^{\prime}$ end of the giant exon and the variation in banding pattern among the allopatric populations of the three species of Mytilus appears to be diagnostic
(Table 1). We have analysed the segregation of the Glu-5' marker in pair-matings of $M$. edulis and $M$. trossulus provided by Dr E. Zouros and find that the patterns of segregation are consistent with Glu being a single autosomal locus. The second marker, Glu- $3^{\prime}$, lies at the $3^{\prime}$ end of the same exon and is highly differentiated among allopatric populations of $M$. edulis and $M$. galloprovincialis. Unfortunately, we have been unable to identify assay conditions that will allow amplification of this marker from $M$. trossulus.

We have genotyped mussels from allopatric populations of $M$. edulis and $M$. galloprovincialis using both the Glu-5' and Glu-3' markers. In all cases $(n=142)$ an individual's $G l u-5^{\prime}$ genotype was identical to its Glu-3' genotype. However, nearly 20 per cent of the mussels collected from the hybrid populations in Whitsand Bay, UK, had genotypes at the two markers that did not correspond, indicating the possibility that recombination or gene conversion has occurred between the $5^{\prime}$ and $3^{\prime}$ ends of the Glu gene. It is possible, however, that rather than being the result of intragenic recombination these genotypes are produced by a single base pair change that eliminates the DdeI restriction site from $M$. edulis Glu- $3^{\prime}$ alleles or creates a restriction site in M. galloprovincialis Glu-3' alleles. We performed two experiments to assess this possibility. First, we cloned and sequenced the Glu-3' PCR products for two mussels which were homozygous for alternate alleles at 


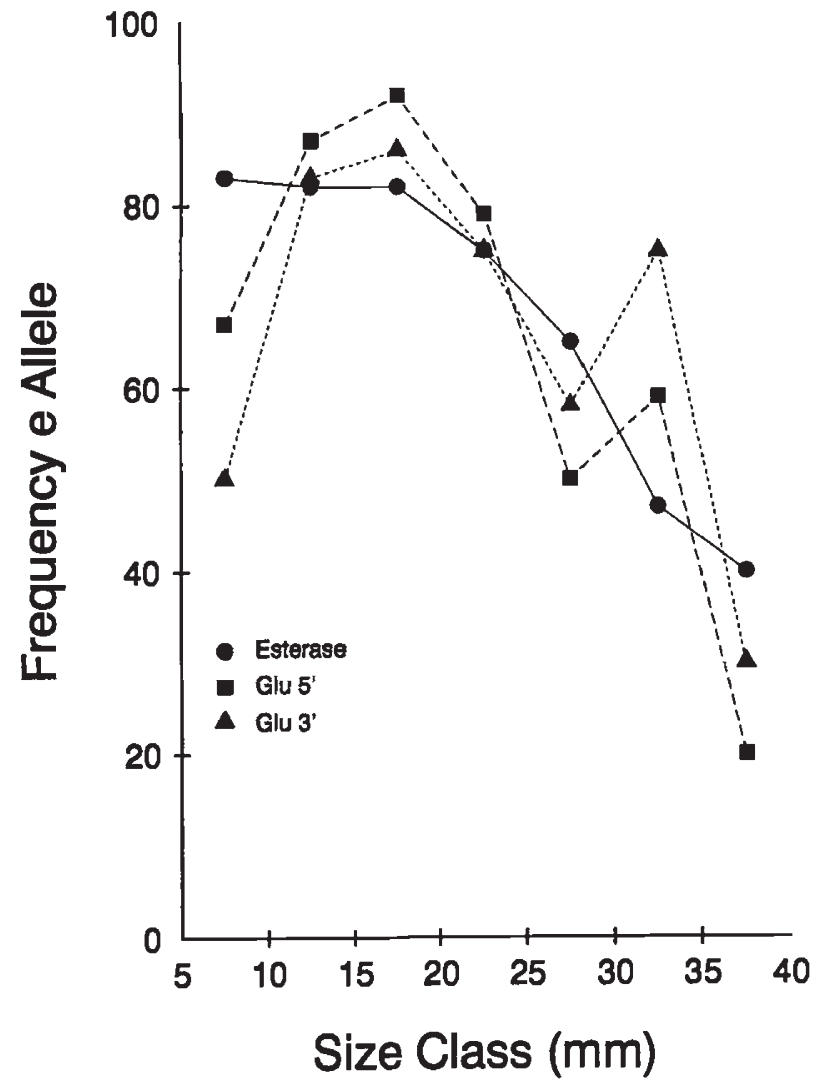

Fig. 4 Frequency of Mytilus edulis (e) alleles at the Esterase-D (Est), Glu-5' and Glu-3' markers as a function of size for the Whitsand Bay, UK, hybrid zone population. For estimating allele frequencies at the $G l u-5^{\prime}$ marker, $M$. edulis-specific $350 \mathrm{bp}$ and $380 \mathrm{bp}$ products were treated as separate alleles whereas the $M$. galloprovincialis $300 \mathrm{bp}$ and $500 \mathrm{bp}$ products were assumed to be produced by a single allele (see text). Thus, mussels with $350 \mathrm{bp}, 380 \mathrm{bp}$, or $350 / 380$ bp banding patterns were scored as $M$. edulis homozygotes, those with 300 bp patterns were scored as M. galloprovincialis homozygotes and those with a $300 \mathrm{bp}$ band in combination with either the 350 bp or 380 bp band were scored as heterozygotes.

Glu-5' but were putative heterozygotes at Glu-3'. These two mussels carried distinct $M$. galloprovincialis and M. edulis alleles at the Glu-3' marker (Fig. 3) indicating that they each carried recombinant alleles. Secondly, we used the restriction enzymes $M s e I$ and NdeI to analyse PCR products of the Glu-3' marker from individuals that exhibited putative recombinant phenotypes. The Glu-3' allele from M. galloprovincialis contains restriction sites for both $\mathrm{MseI}$ and $N d e I$ which are absent in the $M$. edulis allele. If these animals contain $M$. edulis alleles that have lost the DdeI site or $M$. galloprovincialis alleles that have gained the site, they should remain homozygous at

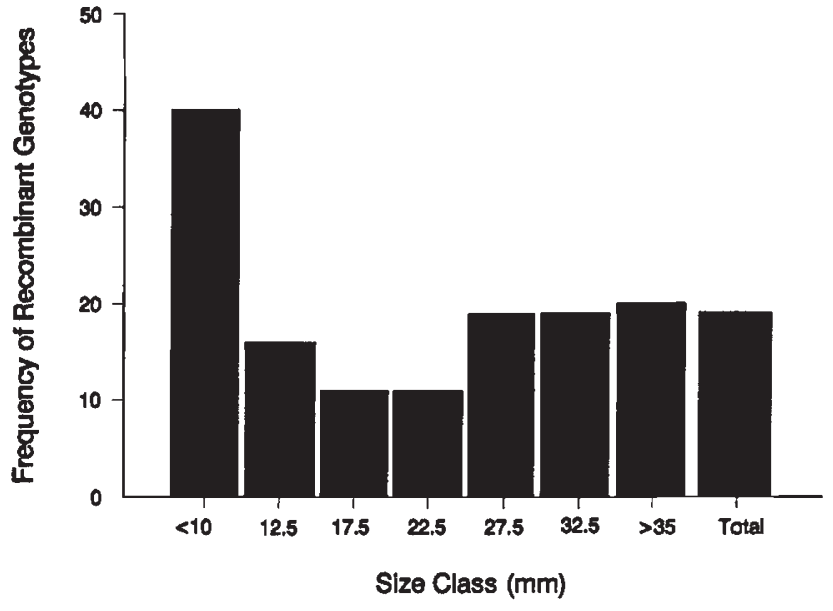

Fig. 5 Frequency of recombinant $G l u$ genotypes as a function of size in the Whitsand Bay, UK, population of Mytilus.

the other two restriction sites. If an individual is a heterozygote for the $D d e I$ site because of recombination between the Glu-5' and Glu- $3^{\prime}$ markers then the MseI and NdeI sites should also be heterozygous. As these two restriction sites occur on either side of the DdeI site it is possible for recombination within the Glu-3' marker to generate a heterozygote at one restriction site but not the other. In all cases $(n=21)$, putatively recombinant mussels were heterozygous for both the $\mathrm{MseI}$ and $N d e \mathrm{I}$ restriction sites indicating that they represent alleles in which recombination has occurred between the Glu-5' and Glu-3' markers.

The observed frequency of genotypes that are heterozygous for recombinant Glu alleles (approximately 20 per cent) suggests that the frequency of recombinant alleles is approximately 10 per cent. The presence of rare or novel allozyme alleles has been noted in many hybrid zone studies (see Barton \& Hewitt, 1985) and rare electromorphs may occasionally attain high frequencies within hybrid populations (Woodruff, 1989). Woodruff (1989) has discussed possible mechanisms for the production of novel alleles in hybrid individuals including posttranslational modification of proteins, mutation and intragenic recombination. Recently, Bradley et al. (1993) demonstrated that a novel alcohol dehydrogenase allele in Geomys was produced through a single point mutation. In our study of Mytilus, we have shown that the appearance of a novel Glu allele in a hybrid population is not caused by a single base substitution but is probably an intragenic recombination. The mechanisms that maintain the high frequency of novel alleles in hybrid populations, whether arising from mutation or recombina- 
tion, are currently being debated. However, the high frequency of recombinant Glu alleles in Whitsand Bay suggests that hybridization is relatively common and has been occurring for a substantial period of time. In contrast, intragenic recombination is expected to be rare in hybrid zones that have recently been established or in regions of sympatry where hybridization is infrequent and would lead to a low frequency of novel alleles (Woodruff, 1989).

Each pair of the three sibling species of Mytilus is highly differentiated at three to four enzyme-coding genes but none of these loci is completely diagnostic. The Glu gene provides an additional marker which is highly differentiated among these sibling species that can be used in the taxonomy of Mytilus and in studies of hybridization among species. Hybridization occurs wherever two blue mussel species co-occur and additional genetic markers will be invaluable in assessing the dynamics of these hybrid zones. For example, in mussel populations containing hybrids of $M$. edulis and $M$. galloprovincialis in south-west England, viability selection generates a strong relationship between allozyme allele frequencies and size (Skibinski, 1983; Gardner \& Skibinski, 1988, 1991; Wilhelm, 1993). In a hybrid population at Whitsand Bay the Glu gene exhibits a virtually identical relationship between allele frequency and size, as do several allozyme loci, indicating that the Glu gene is at least as sensitive as enzyme-coding genes in revealing patterns of natural selection in this hybrid population.

The similarity in behaviour between the Glu gene and allozyme loci may indicate that these genes are all linked and mark a single section of the genome that is under selection in the hybrid population at Whitsand Bay. Beaumont (1994), for example, demonstrated linkage among some allozyme loci in $M$. edulis, although he did not specifically address linkage among the three allozymes used in this study. It is unlikely that the Glu gene is strongly linked to any of the three allozyme loci used in this study. First, the allozyme loci examined here (Est, Lap and $\mathrm{Mpi}$ ) do not appear to be closely linked; recombinant genotypes are found frequently within hybrid populations (Wilhelm, 1993) and different allozyme alleles do not cosegregate with physiological differences between $M$. edulis and M. galloprovincialis to the same degree (Hilbish et al., 1994). Secondly, recombinants between the Glu markers and the allozyme genes were frequently observed. Finally, alleles formed by recombination within the Glu gene appear to be relatively common, indicating that linkage between this gene and other loci is unlikely. These data suggest that Glu is likely to segregate independently of other gene loci that are highly differentiated between $M$. edulis and $M$. galloprovincialis.

PCR-based assays of genetic markers may also be valuable because they are more sensitive than allozyme methods and can be used in the routine analysis of minute quantities of material, such as mussel larvae or spat. Corte-Real et al. (1994a,b) have recently reported a PCR assay of the calmodulin gene and demonstrated that it can be used to analyse individual mussel larvae. Using the procedures described above we have successfully used both Glu markers to assay recently settled mussel spat that were preserved in ethanol using the procedures outlined in this paper (data not shown). The PCR-based assay of the Glu gene, described here, provides a tool by which the exchange of larvae among genetically differentiated mussel populations and the strength of natural selection within hybrid larval populations can be assessed.

\section{Acknowledgements}

We thank R. Burton, C. Langdon, P. Gaffney, P. Cislo, B. Bayne, A. Day and E. Zouros for providing some of the mussel samples used in this work. This project was funded by NSF grant OCE-9203320 to T.J.H.

\section{References}

AVise, J. C. 1994. Molecular Markers, Natural History and Evolution. Chapman and Hall, New York.

BARTON, N. H. AND HEWITT, G. M. 1985. Analysis of hybrid zones. Ann. Rev. Ecol. Syst., 16, 113-148.

BEAUMONT, A. R. 1994. Linkage studies in Mytilus edulis, the mussel. Heredity, 72, 557-562.

BRADLEY, R. D., BULL, J. J., JOHNSON, A. D. AND HILlis, D. M. 1993. Origin of a novel allele in a mammalian hybrid zone. Proc. Natl. Acad. Sci. U.S.A., 90, 8939-8941.

CORTE-REAL, H. B. S. M., DIXON, D. R. AND HOLLAND, P. W. H. 1994a. Intron-targeted PCR: a new approach to survey neutral DNA polymorphism in bivalve populations. Mar. Biol., 120, 407-413.

CORTE-REAL, H. B. S. M., HOLlAND, P. W. H. AND DIXON, D. R. 1994b. Inheritance of a nuclear DNA polymorphism assayed in single bivalve larvae. Mar. Biol., 120, 415-420.

FILPUlA, D. R., LEE, S. M., L1NK, R. P., STRAUSBERG, S. L. AND STRAUSBERGR, R. L. 1990. Structural and functional repetition in a marine mussel adhesive protein. Biotechnol. Prog., 6, 171-177.

FREEMAN, K. R., PERRY, K. L., DIBACCO, T. G. AND SCARRATT, D. J. 1994. Observations on two Mytilid species from a Nova Scotian mussel farm. Can. Tech. Report Fish. Aquat. Sci., 1969, 1-47. 
GARDNER, J. P. A. AND SKIBINSKI, D. O. F. 1988. Historical and size-dependent genetic variation in hybrid mussel populations. Heredity, 61, 93-105.

GARDNER, J. P. A. AND SKIBINSKI, D. O. F. 1991. Biological and physical factors influencing genotype-dependent mortality in hybrid mussel populations. Mar. Ecol. Prog. Ser. 71, 235-244.

GOSLING, E. M. 1992a. Systematics and geographic distribution of Mytilus. In: Gosling, E. M. (ed.) The Mussel Mytilus: Ecology, Physiology, Genetics and Culture, pp. 1-20. Elsevier, Amsterdam.

GOSLing, E. M. 1992b. Genetics of Mytilus. In: Gosling, E. M. (ed.) The Mussel Mytilus: Ecology, Physiology, Genetics and Culture, pp. 309-382. Elsevier, Amsterdam.

HARRISON, R. G. AND RAND, D. M. 1989. Mosaic hybrid zones and the nature of species boundaries. In: Otte, D. and Endler, J. A. (eds) Speciation and its Consequences, pp. 111-133. Sinauer Associates, Sunderland, MA.

HEWITT, G. M. 1990. Divergence and speciation as viewed from an insect hybrid zone. Can. J. Zool., 68, $1701-1715$.

HILBISH, T. J., BAYNE, B. L. AND DAY, A. 1994. Genetics of physiological differentiation within the marine mussel genus Mytilus. Evolution, 48, 267-286.

INOUE, K. AND ODO, s. 1994. The adhesive protein cDNA of Mytilus galloprovincialis encodes decapeptide repeats but no hexapeptide motif. Biol. Bull., 186, 349-355.
KOEHN, R. K. 1991. The genetics and taxonomy of species in the genus Mytilus. Aquaculture, 94, 125-145.

McDONALD, J. H., SEED, R. AND KOEHN, R. K. 1991. Allozymes and morphometric characters of three species of Mytilus in the Northern and Southern Hemispheres. Mar. Biol., 111, 323-333.

SKIBINSKI, D. O. F. 1983. Natural selection in hybrid mussel populations. In: Oxford, G. S. and Rollinson, D. (eds) Protein Polymorphism: Adaptive and Taxonomic Significance, pp. 283-298. Academic Press, London.

SKIBINSKI, D. O. F., CROSS, T. F. AND AHMAD, M. 1980. Electrophoretic investigation of systematic relationships in the marine mussels Modiolus modiolus L., Mytilus edulis L. and Mytilus galloprovincialis Lmk. (Mytilidae: Mollusca). Biol. J. Linn. Soc., 13, 65-73.

WAITE, J. H. 1992. The formation of mussel byssus: anatomy of a natural manufacturing process. In: Case, S. T. (ed.) Structure, Cellular Synthesis and Assembly of Biopolymers. Results and Problems in Cell Differentiation, vol. 19, pp. 55-74. Springer, Berlin.

wilhelm, R. 1993. Genotype-Specific Selection within a Hybrid Population of the Mussel Genus Mytilus. Masters thesis, University of South Carolina, Columbia, SC.

wOODRUFF, D. S. 1989. Genetic anomalies associated with Cerion hybrid zones: the origin and maintenance of new electromorphic variants called hybrizymes. Biol. J. Linn. Soc., 36, 281-294. 